\title{
Impact of Personal and Environmental Factors on the Effectiveness in Academic E-Learning Systems; A Case Study: E-Learning System of The University of Sistan and Baluchestan
}

\author{
Fatemeh Saghafi, ${ }^{1,}$ Saeideh Ansari, ${ }^{2}$ and Seyed Morteza Syedin ${ }^{2}$ \\ ${ }^{1}$ Assistant Professor of Faculty of Management of University of Tehran, IR Iran \\ ${ }^{2}$ Master of Science in IT management, Sisten Baluchestan University, IR Iran \\ "Corresponding author: Fatemeh Saghafi, Assistant Professor of Faculty of Management of University of Tehran, IR Iran, E-mail: fsaghafi@ut.ac.ir
}

Received 2015 September 08; Revised 2016 June 25; Accepted 2016 June 30.

\begin{abstract}
Introduction: After several decades, internet has greatly transformed the world around us. In recent years, although E-learning systems (which are based on cyberspace) are more frequently used as the basis for learning, but in spite of their numerous advantages over the classic methods; they still have a small share in the education ministry and users still prefer the classic methods or at least they do not participate as much as expected in E-learning systems.

Methods: The research orientation of this study is an applied one, whilst the strategy is quantitative and the aim is descriptivesurvey. A questionnaire including 5 demographic and 18 questions were used to collect data in order to examine the research hypotheses. The population of this study is the students of virtual learning branch of university of Sistan and Baluchestan, which are approximately 200 people and according to Morgan table, samples were calculated to be 127 . The research methodology is partial least squares (PLS) therefore Smart PLS software is used for analysis of hypotheses.

Results: Based on the findings, psychological safety communication climate, as well as responsiveness does not have a significant relation with Intention to continue participation. But there are significant relations between Self-efficacy and Satisfaction with Intention to continue participation. Also, psychological safety communication climate and responsiveness affect Intention to continue participation through the moderating effect of participators satisfaction.

Conclusions: The results reveal that the personal factors influencing intention to continue participation and environmental factors affect intention to continue participation through the moderating effect of personal factors. As a result, more attention should be specifically given to personal factors (in this research they are included as satisfaction, and self-efficacy) by managers and professors of e-learning systems.
\end{abstract}

Keywords: Distance Education, Personal Factors, Environmental Factors, E-Learning Systems

\section{Introduction}

The world around us has been transformed by information technology (IT) ever since its early days. The constant development which has been occurring in IT in the last decade has had a great impact on the expansion of E-learning and internet based knowledge representation and internet based learning. Conversely, the constant development of the modern information societies has also had a great deal of impact on classical face to face methods of learning. So whilst there is a much increasing demand for education and learning around the world, the classic face to face methods cannot handle this considerable demand for learning when there is a need for fast and productive communication and feedback (encounter) between the learner and the teacher (1).

Although the needs of the educational institutes (for example universities or colleges) are important but those of the customers or students are also crucial and must be put in viewpoint when the designing and developments of the systems are about to occur. The work of Vaughan and MacVicar has revealed that E-learning like other methods of learning must be put in place with emphasis on the user's needs and if not so, the outcome will most likely be failure of the whole method (2). Constructing the learning system alone is not sufficient and does not signify that it will be embraced and automatically used by students (3). For instance, if the students require doing some kind of team work in the process of learning a particular subject, the teachers should have the authority to allow them stay in contact with each other and should also be given the required contact information involved or responsible for the outcome of the subject or course. The ease of access to classmates and teachers could help the students to have better communications with another and prevent any potential psychological problems like boredom (2). A successful E-Learning process should include effective com- 
munication between the participators (4). The key factors of a successful E-learning process include communication between students, communication of the students with teachers and the group learning which is the direct result of the mentioned communications (5). In recent years, numerous studies have been done to fathom the influential factors regarding the communication between students and users of E-learning (6) systems and the key innovations in the subject; which are crucial to describe the whole situation (7). Current studies (Asiri et al.) have established that substantial factors about the learning systems consist of two separate sets of internal and external variables. The study states that internal variables consist of user related factors like general orientation, belief about the whole idea of E-learning systems and technological adaptability of the individual and the external variables are organizational, technical and technological obstacles (8). In a recent study (Palvic et al.) they were trying to establish a relationship between most effective factors which have a say in E-learning systems. In the process of the research two sets of qualitative questionnaires were distributed among 534 users of online learning systems, 25 affecting factors on the adoption of these systems, including usability, user interface quality, quality of content, satisfaction, facilitating conditions, availability, responsibility, performance, reliability, compatibility and carefulness were chosen (9). Chen and Tseng has used Ajzen model of Technology Acceptance to study the affecting factors on the adoption of web-based learning systems. In that study, incentive of use, anxiety in using computer (new technologies), and self-efficacy in using the internet were perceived (identified) as core affecting factors in usefulness and ease of use of the E-learning systems (1). Newton and Sawang have revealed in their study that specifications which are effective on the participation of people in E-learning systems are distributed in two categories, personal ones: self-efficiency and willingness to change and E-Learning specifications: including reliability and complexity of the e-learning system (10).

In a recent study, Al-hawari and Mouakket (11) have concluded that contributing factors are based on two main categories which include the TAM factors (technology acceptance model) (ease of use, usefulness) and external factors (Joy and Design) (11). In another study, Lee and Pituch, have proposed that the three systematic factors which affect the use of E-Learning are: application (capabilities), the mutual engagement and response (feedback). Moreover, the studies have revealed that all of these factors have a positive impact on both actual uses of e-learning (4). Dasgupta et al. in a study have examined the use of TAM in acceptance of the Collaboration technologies by users. The results have revealed that this model can evaluate the use of new internet based platforms with an acceptable degree of certainty. Moreover in their study familiarity with ICT, technological Self effectiveness has been introduced as one of the factors affecting the adoption of electronic collaboration technologies (12). In a study conducted by Melendez et al.; they discovered that the other factors (variables) affecting the acceptance of E-learning system by students in addition to TAM would be self-efficacy and the attitude toward E-learning and willingness to use E-learning systems (13). In addition to previously conducted research in this study, Ong et al. added the perceived credit to the TAM model and employed it as a tool to study the acceptance of the E-learning systems in the engineering community (14). Lee et al. added 4 more other factors (personal, organizational, working characteristics and subjective norms) which were in direct relation with the perceived ease of use and perceived usefulness, to study the adoption (acceptance) of E-learning systems by the users (15). Zhang et al. introduced the variable of self-efficacy as one of the key factors influencing the continued participation of the students in the systems. They also stated in their research that in addition to environmental factors in e-learning systems, they studied the perceived responses and communication atmosphere and discovered that these factors would positively influence the self-efficacy of students in their use of the online chat rooms (forums) (6). In reference to Asiri et al. the affecting factors on acceptance (adoption) of new technologies by users are categorized into 2 sets, internal and external (8). In 2010, Al-hawari and Mouakket stated that these factors could be rearranged into TAM (which are based on the attitudes of the users) and external factors (11). Zhang et al. have declared that the participation in E-Learning systems itself; is based on 2 different sets of factors, personal and environmental (6). According to the Bandura Sociological Theory (which is a widely accepted model for individual behavior), self-efficacy is the key element in which different sets of skills including cognitive skills, social skills, emotional and behavior capacity which are required to achieve different objectives, are to be effectively organized (16). Self-efficacy will enable people to thoroughly use their capabilities and skills. In the criteria of this research, self-efficacy is interpreted as selfconfidence of the learner in learning in the E-Learning environment (17). Self-efficacy of the students is a personal key factor which arises from the belief in their skills and is related to their motivation, cognitive resources, period of performance and special requests (18). According to the literature review, Self-efficacy is one of the factors influencing the adoption of new technologies $(1,6,10,13)$. Student's satisfaction can affect their engagement in e-learning systems (and online forums in the related criteria). Usually, the satisfaction of users of a system is crucial for evaluating the performance of the system in the short and long term 
as well as the willingness to readmission (19). Langerak et al. believe that electronic satisfaction and loyalty are key factors affecting participation in virtual communities (20). Psychological security of the communications is another vital factor in the desired community that has features such as "support, having a safe space or freedom, trust, mutual respect and acceptance of risk" (21). Psychological security of the communications is a community in which interpersonal relationships are accepted without any potential risks. Edmondson defines psychological security of the communications as: "the perception of members about interpersonal communications whilst everybody feels comfortable about being themselves (22). "He also states that "This expression is not about a feeling toward freedom of choice and behavior nor about a constant positive effect but it's also a sense of confidence which makes you believe the team does not want to embarrass anyone, reject or punish them when they try to talk (23)".

In a learning environment, psychological security of communications can be explained as the feeling that enables the student to do their duties without the fear of any harm arising in their societal figure or career (professional status). Diverse studies have revealed that psychological security of communications is important for the acts of sharing information, healthy relations and good teamwork $(23,24)$.

Perceived operational response refers to the ability to attract successful interactions between participants. One way to improve the conditions of the learning environment is to focus on the nature of communication and the development of interactions which is defined as a central element of the dynamics of the process of E-learning (25). In the e-learning environment, communication is not only to free students from isolation but also to increase the rate of understanding of the material taught in the program by students.

Determining the level of understanding of the course content by the student is not only done by reading, hearing, or seeing, but the teacher should be able to have an interactive relation with the student, carefully treat him/her and ask questions to be able to comprehend if the student has understood the material that was taught or not (26).

The researchers believe that engagement between learners and classmates and developing relationships with one another are the factors which have great influence on the user's motivation to continue participating in Elearning environments (17). According to Langerak et al. effective communications increases satisfaction of the people of virtual environments and this increase will thereby result in increasing willingness of the people participating in these environments (20).

In addition, Cheng in his research discovered that the communications between learners, learners with the teacher and learners with the system have a positive relationship with the willingness of the students to participate in the E-Learning system as well (27) (Table 1).

As can be seen, the summary of the literature review is presented above in Table 1. TAM model in technology acceptance has been used in each of these researches. As it is seen, all of these researches have used 4 important contributing factors of self-efficiency, user satisfaction, psychological security of the communications and perceived accountability in different manners.

According to what has been discussed, influential factors affecting the continuous participation of students in E-learning systems are divided into two major disciplines, individual and environmental. The main aim of this study is to evaluate the effects of aforementioned factors on learner's participation in these systems. Personal factors are self-efficacy, and user satisfaction and environmental factors are psychological security of the communications and perceived accountability. Therefore, the research model of this research is presented in Figure 1 in accordance to the theoretical framework given in the introduction.

This study has two main hypotheses and 10 secondary hypotheses which are also stated in Figure 1.

The main hypotheses are:

1. Personal factors have positive significant effect on the intention to continue to participate in E-Learning systems.

2. Environmental factors have positive significant effect on intention to continue to participate in e-learning systems.

Secondary hypotheses are:

1. Self-efficacy has a positive significant impact on the intention to continue to participate (contribute).

2. Satisfaction has a positive and significant effect on the intention to continue to contribute.

3. The psychological security of the communications has a positive and significant effect on the intention to continue to contribute.

4. Perceived accountability has a positive significant impact on the intention to continue to contribute to the system.

5. Perceived accountability has a positive and significant impact on user satisfaction.

6. Perceived accountability has a positive and significant effect on self-efficacy.

7. Self-efficacy has a positive and significant impact on user satisfaction.

8. The psychological security of the communications has a positive and significant impact on user satisfaction. 


\begin{tabular}{|c|c|c|c|c|}
\hline \multicolumn{2}{|l|}{ Environmental } & \multicolumn{2}{|c|}{ Personal } & \multirow[t]{2}{*}{ Literature Review } \\
\hline Perceived Accountability & $\begin{array}{l}\text { Psychological security of the } \\
\text { communications }\end{array}$ & Satisfaction of the users & Self-Efficacy & \\
\hline $\begin{array}{l}\text { Organizational and } \\
\text { technical factors }\end{array}$ & Societal factors & The degree of Compatibility & Educational beliefs & Asiri et al. (8) \\
\hline $\begin{array}{l}25 \text { factors influencing } \\
\text { admission }^{\mathbf{a}}\end{array}$ & & & & Pavlic et al. (9) \\
\hline Stress using technology & - & Perceived usefulness & Self-Efficacy & Chen and Tseng (1) \\
\hline $\begin{array}{l}\text { Reliability and complexity } \\
\text { of the E-Learning system }\end{array}$ & - & - & $\begin{array}{l}\text { Self-Efficacy Willingness } \\
\text { toward change }\end{array}$ & Sawang et al. (10) \\
\hline Design & Joy & Usefulness & Ease of use & Al-hawari and Mouakket (11) \\
\hline Communication & Accountability & - & Capability & Pituch and Lee (4) \\
\hline- & - & - & Electronic Self-Efficacy & Dasgupta et al. (12) \\
\hline- & - & Willingness to use & Self-Efficacy & Padilla-Melendez et al. (13) \\
\hline- & Perceived credit & & & Ong et al. (14) \\
\hline- & Working Features & Perceived usefulness & $\begin{array}{l}\text { Subjective norms Perceived } \\
\text { ease of use }\end{array}$ & Lee et al. (15) \\
\hline \multirow[t]{2}{*}{ Perceived accountability } & Communication state & - & Self-Efficacy & Zhang et al. (6) \\
\hline & Loyalty & Satisfaction & - & Langerak et al. (20) \\
\hline
\end{tabular}

${ }^{\mathrm{a}}$ Usability, user interface quality, quality of the content, satisfaction, facilitating conditions, availability, accountability, efficiency, reliability, compatibility and accuracy.

9. The psychological security of the communications has a positive and significant effect on perceived accountability.

10. The psychological security of the communications has a significant effect on Self-efficacy of the relationship.

\section{Methods}

The research orientation of this study is applied research, whilst the strategy is quantitative and the aim is descriptive-survey. The present research was conducted in 2014. The data collection tool was a questionnaire made with 23 questions based on the five points Likert-type Spectrum. 5 of the questions are used to study demographic data and 18 are used to study the aforementioned research hypothesis whilst question 1 through 6 are regarding the intention to continue to participate, 7 through 9 are concerning perceived accountability, 10 to 12 are regarding the psychological security of the communications, 13 and 14 are about self-efficacy and 15 to 18 are to count for the user satisfaction (questionnaire statements stated in Table 1). The views of five experts and professors of information technology management (those who have over 5 years of research in the field of e-learning/teaching or were involved in administrative work) were sought in order to evaluate the content validity of the questionnaire and afterward, the questionnaire was modified. 20 question- naires were distributed among the research population in order to assess its reliability and the Cronbach's alpha coefficient was calculated to be equal to 0.91 .

The population of this study included all students of the virtual branch of the Sistan and Baluchestan University, whom were studying different areas of management. The population size was 200 and so the sample size of 127 was calculated by using Morgan table. 135 questionnaires were randomly distributed between samples in order to avoid any deficiencies. To distribute the questionnaires among students of virtual learning branch of the university since there was no difference between the people and they were all eligible samples to be studied, their names were gotten from the university and were assigned from 1 through 200 and 65 of them were randomly chosen, then the corresponding email list of these people was extracted from the university database and then, they were emailed the questionnaires. Inclusion criteria were that, the graduate students must have enrolled in virtual branch of Sistan and Baluchestan University and they should have attended a minimum of one semester at the university and they must answer every question in the questionnaire. Due to this limitation, we retrieved 127 filled questionnaires, 2 were unfinished and the others were not properly done so those questionnaires had to be negated. In order to analyze the hypotheses and as a result of the small sample size, partial least squares model was applied in this research by us- 


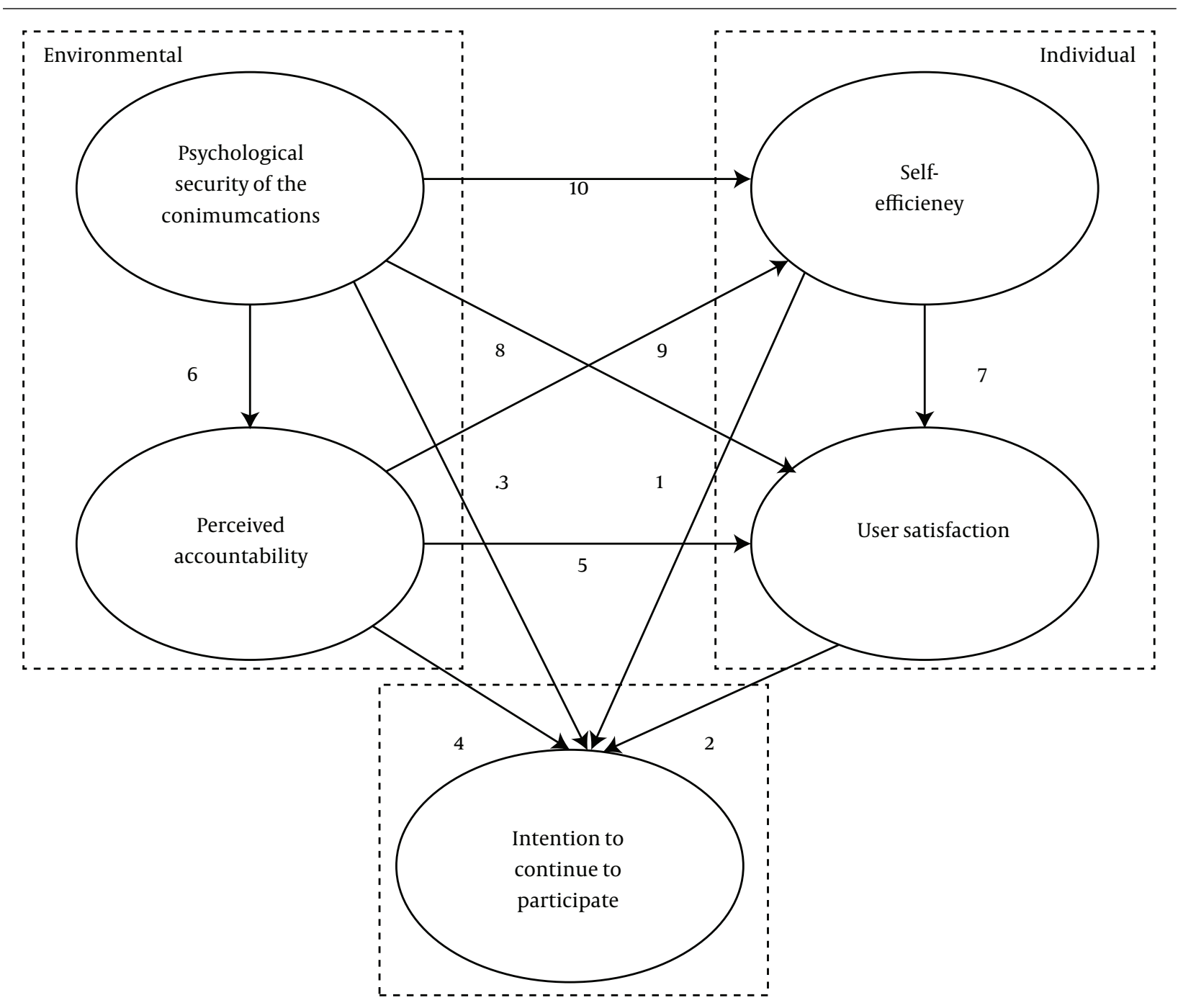

Figure 1. Conceptual Model of Research

ing the Smart PLS firmware version 2.0. After the introduction of factor analysis in 1973, the usage of structural equation systems (SES) became one of the important methods in empirical research. Two methods are involved in structural equation modelling (SEM) of which the first one is based on covariance (CBSEM: covariance-based SEM) and the other one is based on variance. The objective of CBSEM method is converging the theoretical covariance matrix to the observed covariance matrix of the sample and to do so, maximum likelihood and generalized least squares estimation methods are used in this manner. Establishing the default normal distribution factors results in these methods requiring a relatively large volume samples (approximately 10 to 15 times factor)(28).

One of the alternative paths taken to surmount short- ages in obtaining these defaults is using Partial Least Squares. Each of these methods can estimate model parameters quite differently. So the selection of an appropriate analysis of the data is crucial.PLS was used in this research because of two reasons. One:

PLS method includes several OLS (ordinary least square) consecutive regressions thus observations of normal distribution is not required. Two: OLS is used because PLS is best consistent with small samples whilst in CBSEM method the completed questionnaires must be 15 times the number of the factors $(29,30)$. Partial least squares approach is based on the variance and compared to the same techniques as LISREL and AMOS structural equation which requires proper usage of the fewer conditions. And also, there is no limit on the size of the sample and the 
sample size can be 30 or less $(31,32)$. Also it can be used as a powerful method when the sample size and measurable factors are limited and the distribution of variables is uncertain (33).

PLS uses multiple regressions and for each part of the regression of the model, the effect coefficient $(\mathrm{R})$, a significant number $(\mathrm{t})$ and coefficient of determination (R2) are calculated.

A questionnaire was provided to each person. They were free to write down their name and personal information or not. Also, they were assured that the information contained in these questionnaires will always remain confidential.

\section{Results}

According to the findings, 77 of the participators (60.6\%) were male and 50 (39.4\%) were female. 32 (25.19\%) were singles and 95(74.8\%) were married.

The respondents were in the age range of 23 to 44 years, with mean of 31.21 and standard deviation of 1.5. Most of the age distribution was in the range of 32 to 38 years with 45 people (35.4\%). Also all of the respondents were studying their M.sc degree at the virtual branch of Sistan and Baluchestan University in management sciences. Table 2 portrays descriptive statistics which were stated in the questionnaires.

In this study, an index referred to as goodness of fit (GOF) is used to evaluate the suitability of the presented model. Equation 1 shows the index. In equation 1 the value of $\mathrm{R}^{2}$ is equal with the amount of variance relative to each other and AVE is the average variance extracted for each factor.

Equation 1. Index Model

$G O F=\sqrt{\overline{A V E} \times \overline{R^{2}}}$

If the value of GOF exceeds 0.36 it signifies that the fitness of the conceptual model is proper (good). If the value is between 0.25 and 0.36

It represents that the fitness of the model is average and if the amount is less than 0.25 , GOF value reflects the weakness of the model (34).

According to equation 1 and due to the result of running the model in Figure 2, the value of GOF for this model was calculated to be 0.51 , indicating that since it exceeds 0.36 , the model was presented as good fitness and thus, its hypothesis can be evaluated. To evaluate the hypothesis of the study, we analyzed the data using Smart PLS. Figure 2 illustrates the evaluation of the secondary hypothesis in Bootstrapping mode.
The value shown on the arrows in Figure 2 are t-value. If the value is between -1.96 and 1.96 the relation is invalid if not the relation is valid with $95 \%$ accuracy.

According to what have been discussed till now, no positive significant relationship exists between psychological security of the communications and intention to continue to contribute, as well as the perceived accountability and the intention to continue to contribute but a positive significant relationship can be seen, among other variables. The third and fourth secondary hypotheses are rejected and other research hypotheses are validated.

The values expressed on the arrows in Figure 3 illustrate the correlation values and the values expressed inside the circles of each structure; represent the coefficient of determination for the same structure. As it can be perceived in Figure 2, there is a significant positive relationship between psychological security of the communications and self-efficacy and since according to Figure 3 the coefficient of correlation is equal to 0.903 the correlation between these variables is powerful. According to Figure 2 there is a significant positive relationship between self-efficacy and perceived accountability with a t-value equal to 8.385 and according to Figure 3 the correlation coefficient for the above mentioned subject is 0.599. This value for selfefficacy states that the variables of perceived accountability and the psychological security of the communications can dictate $54.5 \%$ of its variance. There is a positive significant relationship between self-efficacy and user satisfaction and the correlation coefficient between these two variables is 0.143 which shows low (not so strong) correlation. Also there is a significant positive relationship between the psychological security of the communications and the user satisfaction with a correlation coefficient of 0.277 and finally, the correlation coefficient between two variables of perceived accountability and user satisfaction, is equal to 0.369. As it can be observed, the coefficient of determination for student satisfaction variable is equal to 0.663 which states that the 3 variables of perceived accountability and the psychological security of the communications and self-efficacy can dictate up to $66.3 \%$ of the aforementioned variable's variance. There is a significant positive relationship between two variables of the intention to continue to contribute and user satisfaction with a good correlation coefficient of 0.610 . Also there is a significant positive relationship between the intention to continue to contribute and self-efficacy with a correlation coefficient of 0.413 and the coefficient of determination for the variable of the intention to continue to contribute is equal to 0.402 which states that these two variables can dictate up to $40.2 \%$ of the aforementioned variable's variance. As earlier stated, there is no relationship between the variables of the psychological security of the communica- 


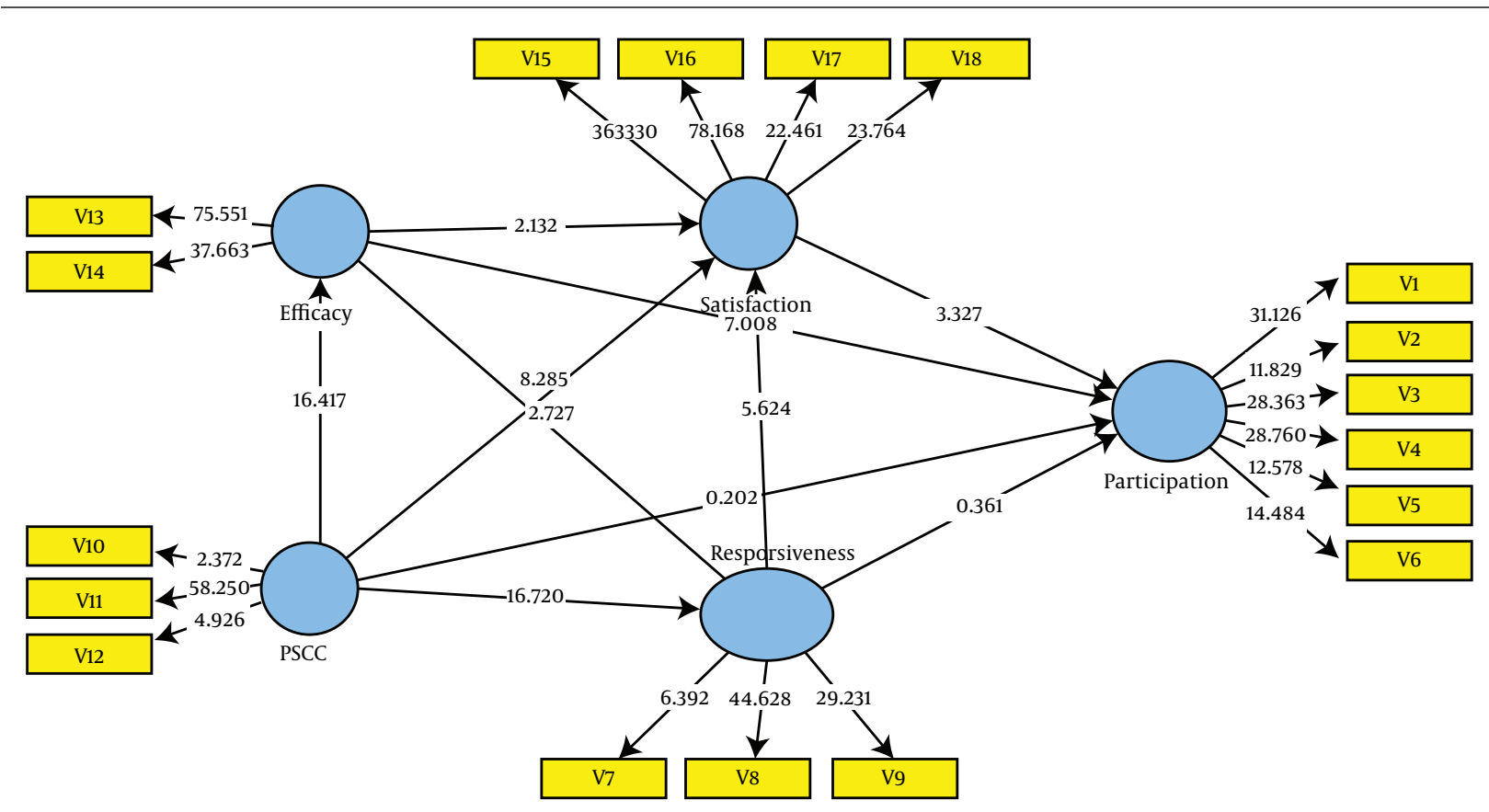

Figure 2. Output of the Smart PLS Software in Bootstrapping mode used to Evaluate the Secondary Hypothesis of the Research

tions and the intention to continue to contribute.

According to Figure 3 and the correlation coefficient of the hypothesis number of 8,2 and 3 and since the multiplication of correlation coefficients of the hypothesis number of 2 and 8 is equal to 0.168 and which is more than the correlation coefficient of the 3rd secondary hypothesis, therefore user satisfaction is the (intervening/moderating/controlling) variable between the psychological security of the communications and the intention to continue to contribute variables and according to the correlation coefficient of the secondary hypothesis number of 2, 4 and 5, since the multiplication of 2 and 5 is equal to 0.225 and since it is above the correlation coefficient of 4 , so the user satisfaction is the (intervening/moderating/controlling) variable between perceived accountability and the intention to continue to contribute. Also to study the effect of personal and environmental factors on the intention to continue to contribute and their relationship toward each other we also employed the Smart PLS firmware. As it can be observed in Figure 4 the t-value of the relationship between personal factors and the intention to continue to contribute is more than 1.96 , so the personal factors do have an effect on the intention to continue to contribute but since the exact coefficient for environmental factors is equal to 1.003 which is lower than the critical value of 1.96 so the environmental factors do not have a say in the matter but not to omit the secondary connection which is that the environmental factors do have a effect on personal factors because the t-value of their relation is more than 1.96 .

According to Figure 5, the correlation coefficient of personal factors and the intention to continue to contribute is equal to 0.720 which indicates that there is a strong correlation between these two variables and so the determination coefficient of the intention to continue to contribute is equal to 0.368 which signifies that it can dictate up to $36.8 \%$ of the intention to continue to contribute variable's variance. Also the correlation coefficient between personal and environmental factors is equal to 0.809 which is a high value, and thus signifies that the environmental factors indeed have a strong effect on personal factors.

According to what has been said till now, the first primary hypothesis of the research is valid and we can certainly say that the personal factors have a positive effect on the intention to continue to contribute in the Elearning systems. The second primary hypothesis which was concerning the effect of environmental factors on the intention to continue to contribute in E-learning systems is invalid. The multiplication of the correlation coefficient of personal and environmental factors is equal to 0.809 and the correlation coefficient of the personal factors and the intention to continue to contribute is equal to 0.720 which implies that the correlation value between environmental factors and the in- 


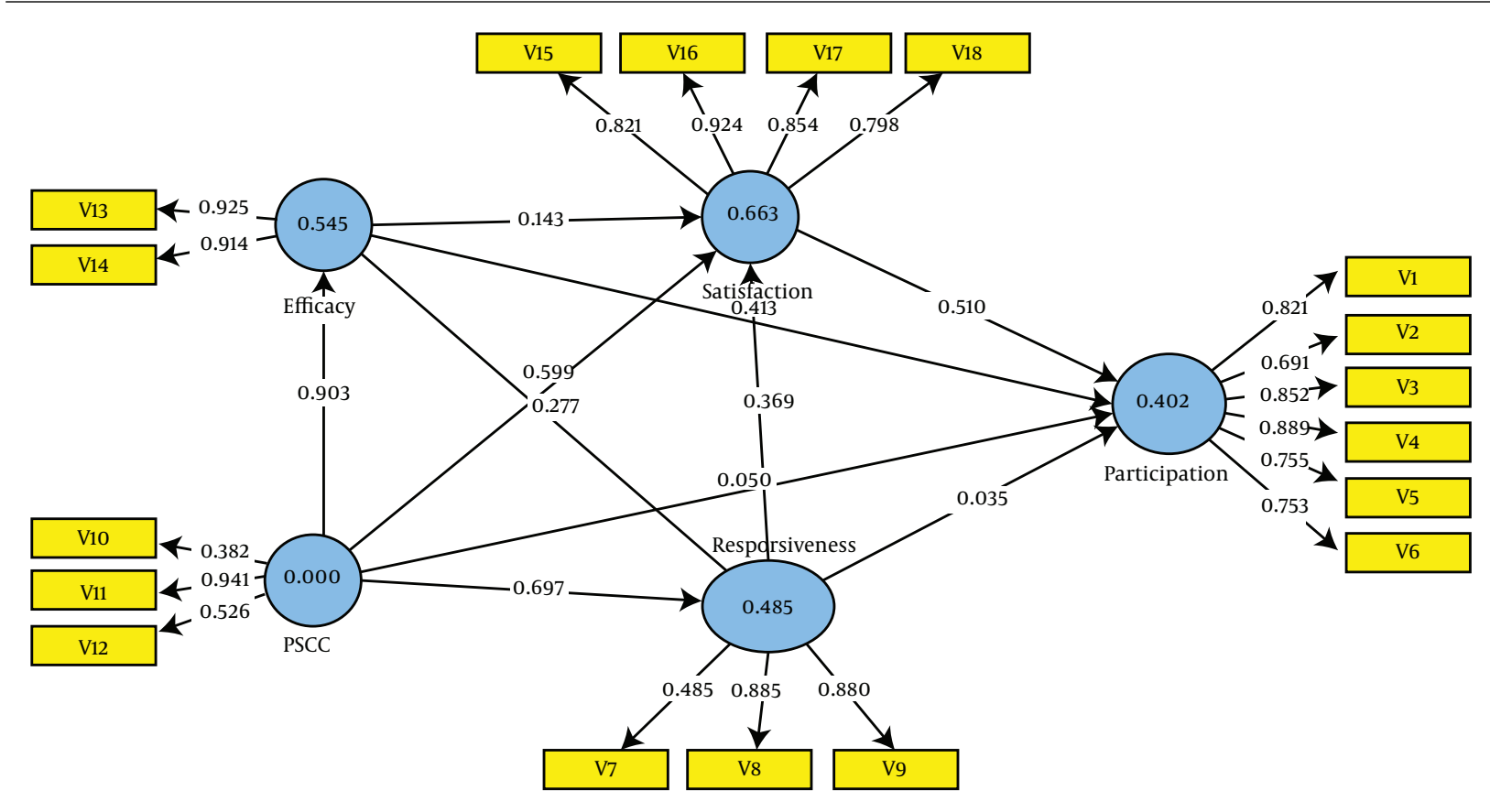

Figure 3. the Output of the Smart PLS in PLS Algorithm Mode to Evaluate the Secondary Hypothesis of the Research

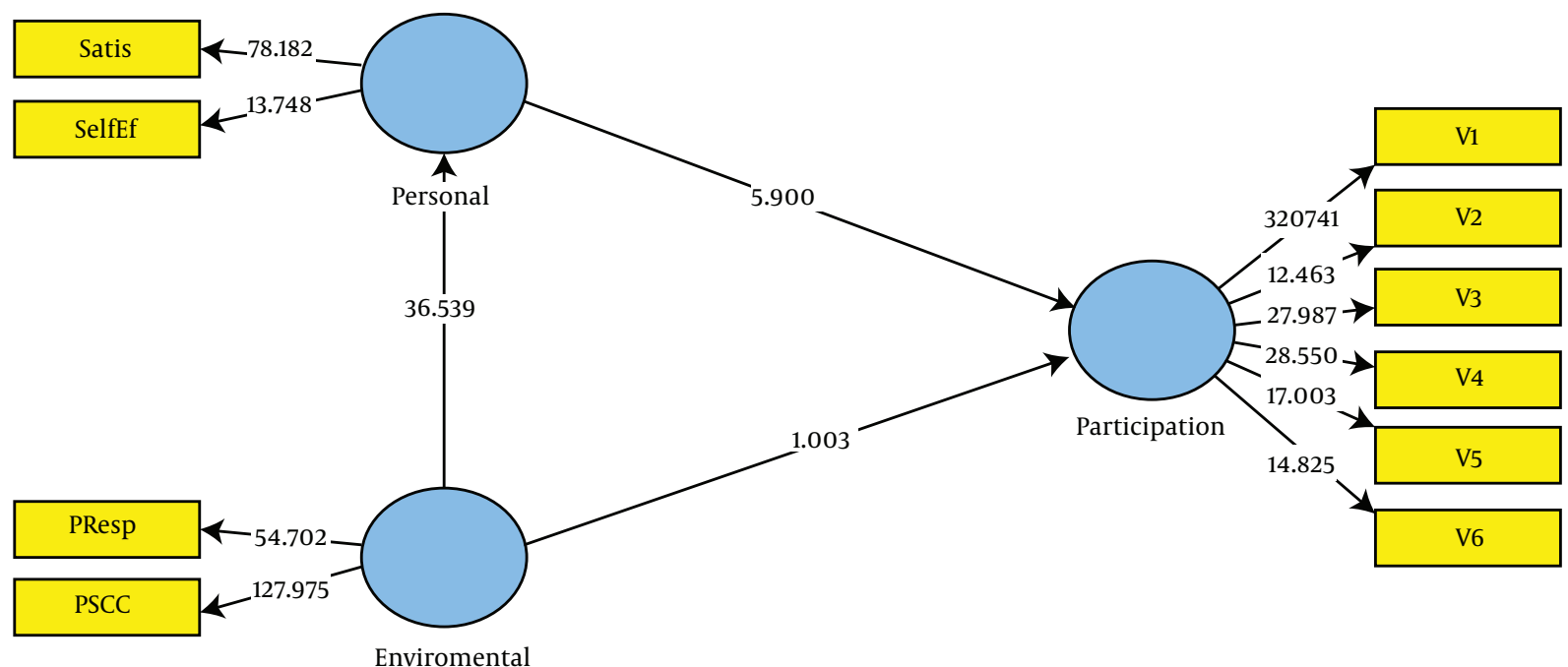

Figure 4. the Output of the Smart PLS Firmware in Bootstrapping Mode to Evaluate the Effect of Personal and Enviromental Factors on the Intention to Continue to Contribute

tention to continue to contribute with the (intervening/moderating/controlling) effect of the personal factors is equal to 0.5824 . Thus finally, it implies that the personal factors (intervening/moderating/controlling) factors between environmental factors and the intention to continue to contribute in E-learning systems.

\section{Discussion and Conclusions}

One of the significant aspects of the growth of ICT is the application of technology in education, which itself is a massive transformation in the social, educational and professional life of humanity in the twenty first century and has revealed a new horizon to the educational institutions including schools and universities Previously, novel tech- 


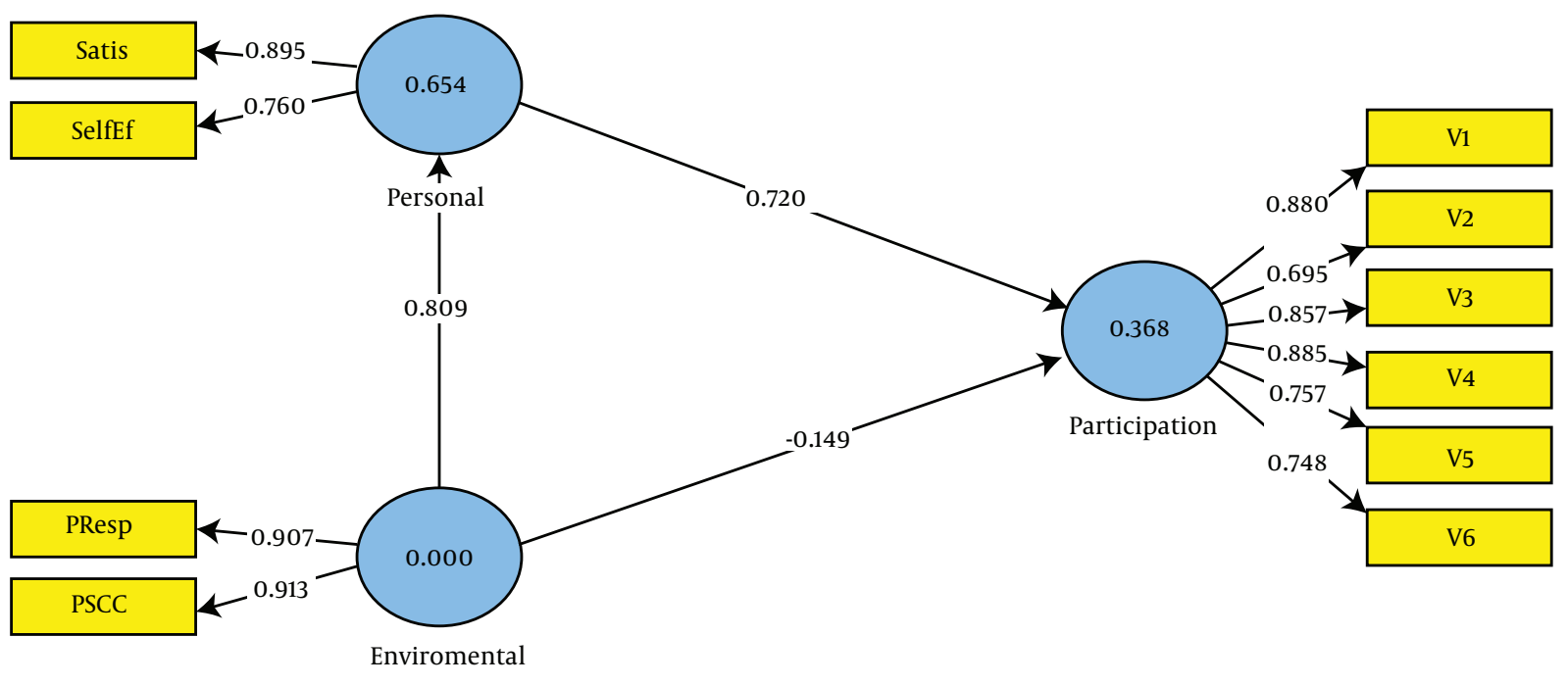

Figure 5. the Output of the Smart PLS Software in PLS Algorithm Mode to Evaluate the Relation Between the Personal and Environmental Factors on the Intention to Continue to Contribute

nological related researches were focused on the growth of the technological and professional aspects, but nowadays the application based researches have become the center of attention. In spite of the huge sum of money spent and invested in the manufacturing, purchasing and transferring of new technologies, numerous reports have indicated that despite the potential of having access to new technologies for users, they are not used as much as intended. In other words, new technologies are not accepted (admitted) by users (35). Creating E-learning systems just by copying them from others without considering the needs of the local stakeholders will not aid its development as fast as necessary. Therefore, understanding the factors that contribute to students' usage of E-learning systems is crucial, and should be properly addressed in the research. Previous studies have identified several factors affecting the user's intention to continue to participate in E-learning systems. Thus, researchers have categorized the important factors affecting the problem into two categories; personal and environmental $(4,9)$. In this study, the personal factors were Self-efficacy and user satisfaction and environmental factors were the psychological security of the communications and perceived accountability and were used to determine their relationship with the intention to continue to participate in educational E-learning system. In line with the findings of this study, personal factors have a significant positive relation to the intention to continue to contribute in educational E-Learning systems. These findings are in accordance to that of Zhang et al. Asiri et al. Swang and Newton, Mouakket and Al-Hawari and Bandura. It signifies that focusing on the personal factors can affect their intention to contribute in the educational E-learning systems. Finding in accord to the second primary hypothesis indicates that environmental factors does not have a positive significant relationship with their intention thus the findings made it obvious that these factors does not also directly affect them but in perspective by becoming (intervening/moderating/controlling) variables they affect the personal ones and so the intention. The first phase of this finding is in contrast with the work of Zhang et al. and Asiri et al. but the indirect effect of environmental factors is in accord with finding of Zhang et al. and Bandura (16). The invalidation of the second primary hypothesis can distinguish that if the technical and environmental infrastructure for the educational E-learning systems is provided, then their image of these systems and capability to use them is the more important controlling factor in their use and intention to continue to contribute to the E-Learning systems. This assumption can be validated due to fact that they are newcomers to the educational system of IRAN. Findings related to the first primary hypothesis of the research indicate that Self-efficacy have a positive significant relation to the learner's intention to continue to contribute to the E-Learning systems. This result is in accord with findings of Chen, Liao, Melendez et al. Chen and Tseng, Zhang et al. and Sawang and Newton. This implies that self-efficacy as a personal factor is presented in their capability to use computers, internet, etc, and their confidence in using an E-learning is effectively reflected in their intention toward continuing to contribute to the E- 
learning system. Findings related to the second secondary hypothesis of the research indicate that satisfaction of the students has a positive relation to their intention to continue to contribute to the e-learning system.

This finding is in line with the findings of Pavlic et al. and Langerak et al (20). The result indicates that increasing the student satisfaction with the E-learning system can make a difference in their attendance and contribution, by using different methods like making a user friendly environment and design and simplicity. According to the third secondary hypothesis of the research, the psychological security of the communications does not have a positive significant relation to the learner's intention to continue to contribute to the E-learning system. This result is not symmetrical to the findings of May et al and Zhang et al. According to the fourth secondary hypothesis of the research, the perceived accountability does not have a positive significant relation with their intention to continue to contribute to the e-Learning system. This is not symmetrical to the findings of Langerak et al. (20) and Cheng et al. (17). As stated earlier, this asymmetry can be explained by E-learning systems being new to the educational system of IRAN. Due to novelty of this technology, personal attitude and personal characteristics of users, including the Self-efficacy have more prominent role than other factors on their intention to continue to partcipate and contribute to these systems. Also Iranian individualistic culture is another factor which contributes to their unwillingness to communicate in these systems and also their intention toward continuing to contribute to the system. According to the findings related to 5th and 6th secondary hypothesis of the research the perceived accountability has a positive significant relation to their Self-efficacy (personal factors) also according to the findings related to the 8th and 10th secondary hypothesis of the research, the psychological security of the communications has a positive significant relation to their Self-efficacy. As it was earlier stated, variables of user satisfaction and Self-efficacy also affect the students' intention, so these factors (personal ones including satisfaction and Self-Efficacy of the students) contribute to the perceived accountability and the psychological security of the communication by becoming moderating variables. This result signifies that having the infrastructure alone is inadequate to increase participation but if environmental factors can affect the student's satisfaction of the system or make his/her self-efficacy to develop then we can expect it to affect their intention toward continuing to contribute to the system. In other words, satisfaction of the student is a moderating variable between these factors and the intention toward continuing to contribute to the system. So the teacher's efforts in creating a conductive environment for students to recognize and discuss their ideas can be a successful endeavor if the student's capabilities like focusing on the format, speed, simplicity and the learning system being smooth are considered and can increase their ability to use computers and the Internet and increase their confidence. According to the 7th secondary hypothesis of the research, Self-efficacy has a positive significant relationship with the satisfaction of the learners. This implies that as much as the users can handle themselves with the E-learning system smoothly, they also feel more satisfied. The 9th secondary hypothesis of the research states that the psychological security of the communications has a positive significant relationship with the perceived accountability. According to this result, as much as the learner is free and not anxious to express him/herself, the more he/she is willing to contribute to the environment. This result is symmetrical to the findings of May et al. (24).

According to the findings of the research hypothesis, personal factors and capabilities affect the students' intention toward continuing to contribute to the system whilst the environmental factors do not. Also the environmental factors also affect the personal ones. Although if the same research could be carried out in a different university, it can be helpful to have a fair comparison.

The results of this study can be helpful for designers, teachers, investors and governors of these E-learning systems. Designers of E-learning systems should focus their design on enabling the user's capacities as much as possible. Teachers should focus on user satisfaction and investors should know that investing their money on the systems in which their goal is to make a better stand in user satisfaction indexes would make their investment worth the effort and more productive. Educational policy makers of the country should assess the quality of the courses by checking their quality and emphasizing the actions toward individualistic parameters of the users.

\section{Supplementary Material}

Supplementary material(s) is available here.

\section{References}

1. Chen HR, Tseng HF. Factors that influence acceptance of web-based elearning systems for the in-service education of junior high school teachers in Taiwan. Eval Program Plann. 2012;35(3):398-406. doi: 10.1016/j.evalprogplan.2011.11.007. [PubMed: 22321703].

2. Sharma K, Pandit P, Pandit P. Critical success factors in crafting strategic architecture for e-learning at HP University. Int J Educ Manag. 2011;25(5):423-52.

3. Hong K, Cheng JLA, Liau T. Effects of system's and user's characteristics on e-learning use: A study at Universiti Malaysia Sarawak. J Sci Math Educ Southeast Asia. 2005;28(2):1. 
4. Pituch KA, Lee YK. The influence of system characteristics on e-learning use. Comput Educ. 2006;47(2):222-44. doi: 10.1016/j.compedu.2004.10.007.

5. Yaghubi NM, Shakeri R. Technology acceptance models; analyticalcomparison approach. Res Manag. 2008;1(2):205-31.

6. Zhang Y, Fang Y, Wei KK, Wang Z. Promoting the intention of students to continue their participation in e-learning systems. Inf Technol People. 2012;25(4):356-75. doi:10.1108/09593841211278776.

7. Gibson CB, Gibbs JL. Unpacking the Concept of Virtuality: The Effects of Geographic Dispersion, Electronic Dependence, Dynamic Structure, and National Diversity on Team Innovation. Administ Sci Q. 2006;51(3):451-95. doi: 10.2189/asqu.51.3.451.

8. Asiri MJ, Mahmud RB, Abu Bakar K, Mohd Ayub AFB. Factors Influencing the Use of Learning Management System in Saudi Arabian Higher Education: A Theoretical Framework. High Educ Stud. 2012;2(2) doi: 10.5539/hes.v2n2p125.

9. Pavlic L. , Pusnik M. , Hericko M. , Sumak B. . Qualitative analysis: Identification of the factors influencing e-learning system acceptance. Third International Conference on Mobile, Hybrid, and Online Learning. .

10. Sawang S, Newton C, Jamieson K. Increasing learners' satisfaction/intention to adopt more e-learning. Educ Train. 2013;55(1):83-105 doi: $10.1108 / 00400911311295031$.

11. Al-hawari MA, Mouakket S. The influence of technology acceptance model (TAM) factors on students' e-satisfaction and eretention within the context of UAE e-learning. Educ Business Soc Contemporary Middle Eastern Issues. 2010;3(4):299-314. doi 10.1108/17537981011089596.

12. Dasgupta S, Granger M, McGarry N. User acceptance of ecollaboration technology: an extension of the technology acceptance model. Group Decision Negotiat. 2002;11(2):87-100. doi: 10.1023/a:1015221710638.

13. Padilla-Melendez A, Garrido-Moreno A, Del Aguila-Obra AR. Factors affecting e-collaboration technology use among management students. Comput Educ. 2008;51(2):609-23. doi: 10.1016/j.compedu.2007.06.013.

14. Ong CS, Lai JY, Wang YS. Factors affecting engineers' acceptance of asynchronous e-learning systems in high-tech companies. Inf Manag. 2004;41(6):795-804. doi: 10.1016/j.im.2003.08.012.

15. Lee YH, Hsieh YC, Ma CY. A model of organizational employees' elearning systems acceptance. Knowledge Base Systems. 2011;24(3):35566. doi: 10.1016/j.knosys.2010.09.005

16. Wagner N, Hassanein K, Head M. Computer use by older adults: A multi-disciplinary review. Comput Human Behav. 2010;26(5):870-82. doi:10.1016/j.chb.2010.03.029.

17. Cheng B, Wang M, Yang SJH, Peng J. Acceptance of competencybased workplace e-learning systems: Effects of individual and peer learning support. Comput Educ. 2011;57(1):1317-33. doi: 10.1016/j.compedu.2011.01.018.

18. Chen M, Liao JL. Correlations among Learning Motivation, Life Stress, Learning Satisfaction, and Self-Efficacy for PhD. Students. J Int Manag
Stud. 2013;8(1):157

19. Salimon MG, Yusoff RZ, Abdullateef AO. The mediating effects of e-satisfaction on the relationship between eBanking adoption and its determinants: A conceptual framework. J Manag Inf System ECommerce. 2014;1(1):95-105.

20. Langerak F, Verhoef PC, Verlegh PWJ, Valck K. Satisfaction and participation in virtual communities. NA Adv Consume Res. 2004;31:56-7.

21. Wu JH, Tennyson RD, Hsia TL. A study of student satisfaction in a blended e-learning system environment. ComputEduc. 2010;55(1):15564. doi: 10.1016/j.compedu.2009.12.012.

22. Hirak R, Peng AC, Carmeli A, Schaubroeck JM. Linking leader inclusiveness to work unit performance: The importance of psychological safety and learning from failures. Leadersh Q. 2012;23(1):107-17. doi: 10.1016/j.leaqua.2011.11.009.

23. van Gennip NAE, Segers MSR, Tillema HH. Peer assessment as a collaborative learning activity: The role of interpersonal variables and conceptions. Learn Instruct. 2010;20(4):280-90. doi: 10.1016/j.learninstruc.2009.08.010.

24. May DR, Gilson RL, Harter LM. The psychological conditions of meaningfulness, safety and availability and the engagement of the human spirit at work. J Occup Organiz Psychol. 2004;77(1):11-37. doi: 10.1348/096317904322915892.

25. de los Ríos Carmenado I, Díaz-Puente JM, Gajardo FG. Behavior competence development through e-learning: experience at the undergraduate level in the context of Aula a Distancia Abierta(ADA) Madrid, Spain.Proc Soc Behav Sci. 2011;15:111-9. doi:10.1016/j.sbspro.2011.03.059.

26. Panda BP, Swain DK. Effective Communications through eGovernance and e-Learning. Chinese Librariansh Int Electron J. 2009(27).

27. Cheng YM. Exploring the roles of interaction and flow in explaining nurses' e-learning acceptance. Nurse Educ Today. 2013;33(1):73-80. doi: 10.1016/j.nedt.2012.02.005. [PubMed: 22405340].

28. Human HA. Structural equation modeling using LISREL software (with changes). Tehran: SAMT Publication; 2014.

29. Hubona GS. Structural equation modeling(SEM) using SmartPLS software: Analyzing path models using partial least squares (PLS) based SEM. AMCIS 2009 Proceedings; 2009.

30. Ringle CM, Wende S, Will A. Smart PLS 2. ; 2005.

31. Ringle CM, Wende S, Becker JM. Smart PLS 3. ; 2015

32. Templeton GF, Byrd TA. Determinants of the relative advantage of a structured SDM during the adoption stage of implementation. Information Technology and Management. 2003;4(4):409-28.

33. Hair JF, Black WC, Babin BJ, Anderson RE, Tatham RL. Multivariate data analysis. Prentice hall Upper Saddle River; 1998.

34. Wetzels M, Odekerken-Schröder G, Van Oppen C. Using PLS path modeling for assessing hierarchical construct models: Guidelines and empirical illustration. MIS Q. 2009:177-95.

35. Omoiee Milan Ghashghagh M, Mehdinezhad V, Yaghoubi N. Assessing Factors Affecting the Tendancy to Use Electronic Learning Systems among Faculty Members. Interdisciplinar J Virtual Learn Med Sci. 2012;2(3):28-38. 


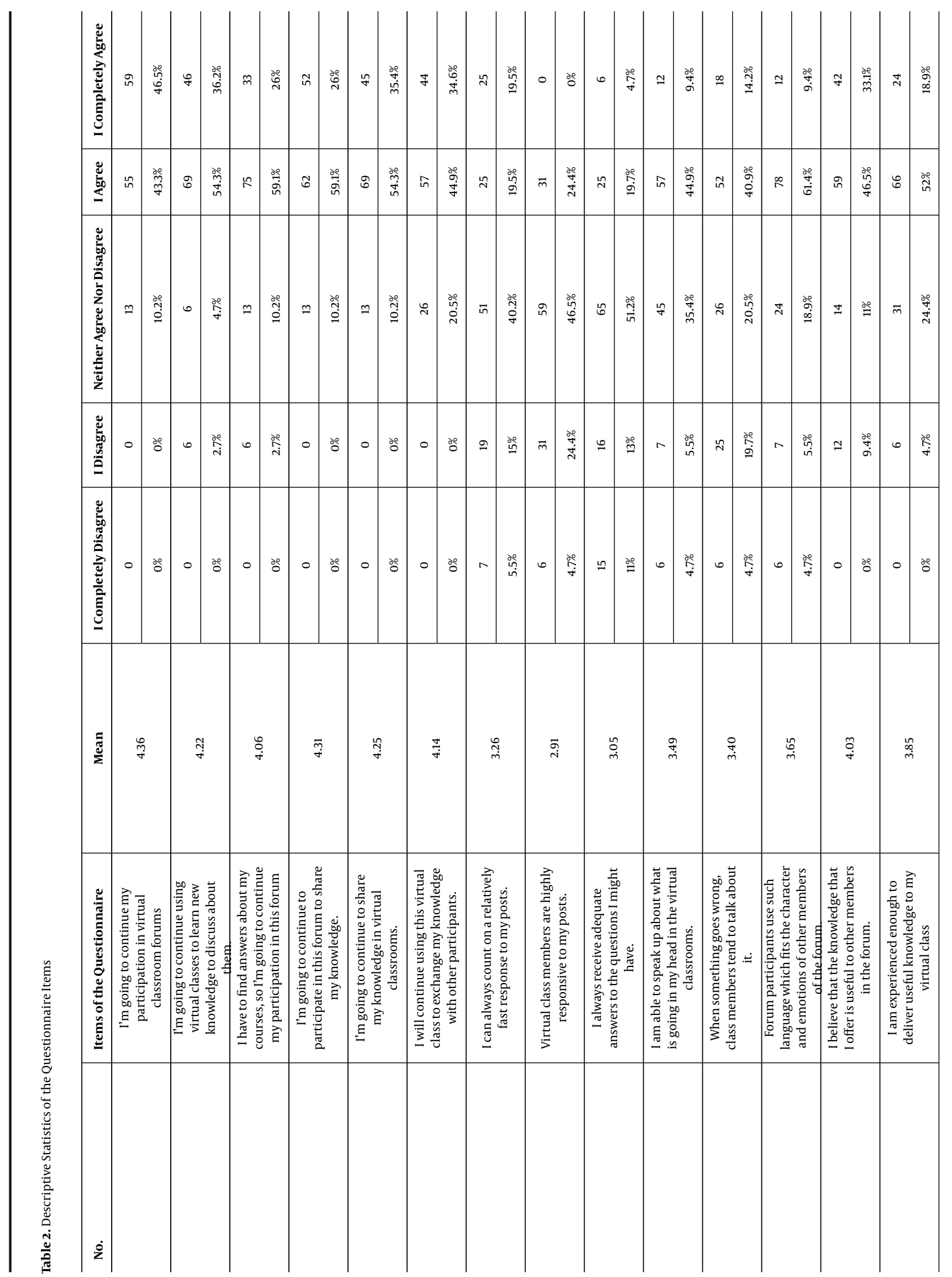




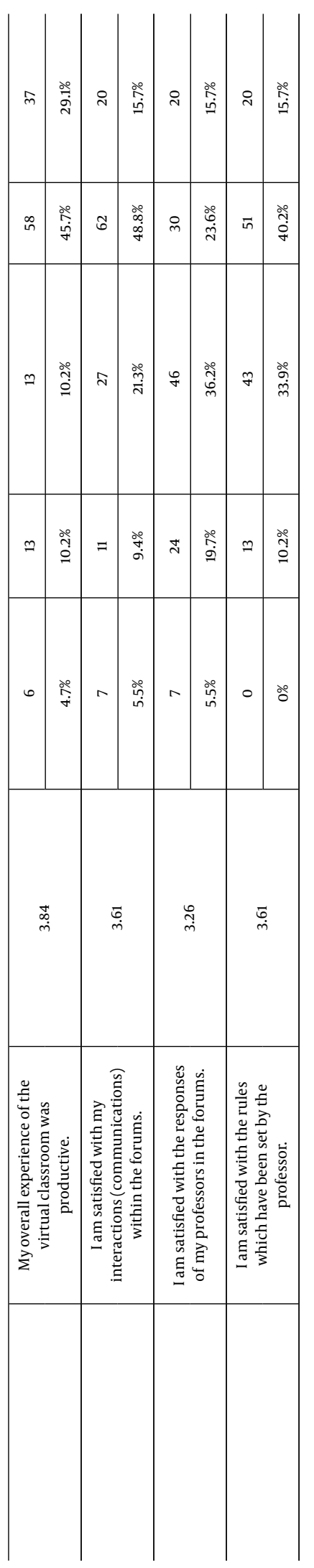

